Article

\title{
The Antioxidant Gallic Acid Inhibits Aflatoxin Formation in Aspergillus flavus by Modulating Transcription Factors FarB and CreA
}

\author{
Xixi Zhao ${ }^{1,+(\mathbb{D})}$, Qing-Qing Zhi ${ }^{1,+}$, Jie-Ying Li ${ }^{1}$, Nancy P. Keller ${ }^{2, *(\mathbb{D}}$ and Zhu-Mei He ${ }^{1, *}$ \\ 1 The Guangdong Province Key Laboratory for Aquatic Economic Animals, School of Life Science, \\ Sun Yat-sen University, Guangzhou 510275, China; zhaoxifdu@163.com (X.Z.); \\ zhiqq3@mail.sysu.edu.cn (Q.-Q.Z.); lijieyingjy@126.com (J.-Y.L.) \\ 2 Department of Medical Microbiology and Immunology, University of Wisconsin-Madison, \\ Madison, WI 53706, USA \\ * $\quad$ Correspondence: npkeller@wisc.edu (N.P.K.); lsshezm@mail.sysu.edu.cn (Z.-M.H.) \\ + These authors contributed equally to this work.
}

Received: 12 June 2018; Accepted: 27 June 2018; Published: 3 July 2018

check for updates

\begin{abstract}
Aflatoxin biosynthesis is correlated with oxidative stress and is proposed to function as a secondary defense mechanism to redundant intracellular reactive oxygen species (ROS). We find that the antioxidant gallic acid inhibits aflatoxin formation and growth in Aspergillus flavus in a dose-dependent manner. Global expression analysis (RNA-Seq) of gallic acid-treated A. flavus showed that $0.8 \%(w / v)$ gallic acid revealed two possible routes of aflatoxin inhibition. Gallic acid significantly inhibited the expression of $\operatorname{far} B$, encoding a transcription factor that participates in peroxisomal fatty acid $\beta$-oxidation, a fundamental contributor to aflatoxin production. Secondly, the carbon repression regulator encoding gene, $c r e A$, was significantly down regulated by gallic acid treatment. CreA is necessary for aflatoxin synthesis, and aflatoxin biosynthesis genes were significantly downregulated in $\triangle c r e A$ mutants. In addition, the results of antioxidant enzyme activities and the lipid oxidation levels coupled with RNA-Seq data of antioxidant genes indicated that gallic acid may reduce oxidative stress through the glutathione- and thioredoxin-dependent systems in A. flavus.
\end{abstract}

Keywords: Aspergillus flavus; antioxidant gallic acid; aflatoxin; farB; creA

Key Contribution: We found that the antioxidant gallic acid inhibits aflatoxin formation in $A$. flavus in a dose-dependent manner: The mechanism was suggested as being through the FarB-mediated $\beta$-oxidation and CreA activity, with some contribution from the pentose phosphate pathway.

\section{Introduction}

Aspergillus flavus is not only a saprotrophic and plant pathogenic fungus but also an opportunistic human and animal pathogen [1]. A. flavus is notorious for production of aflatoxins, which were discovered as the main cause of Turkey-X disease in the 1960s [2]. Since then, substantial efforts have been directed toward understanding the complex mechanisms and the regulation network of aflatoxin biosynthesis.

Primary metabolism has a close link with secondary metabolite synthesis in fungi and, in the case of aflatoxin, several studies have shown that $\beta$-oxidation contributes to high levels of aflatoxin. Fatty acid $\beta$-oxidation in both the peroxisome and mitochondria has a fundamental contribution to toxin production, such as the polyketides, aflatoxin, and sterigmatocystin [3]. Reverberi et al. treated $A$. flavus with bezafibrate, an inducer of peroxisomal $\beta$-oxidation in mammals, and stimulated aflatoxin production. They also introduced a P33 gene into A. flavus to induce peroxisome proliferation, 
which leads to an upregulation of lipid metabolism and higher content of intracellular reactive oxygen species (ROS), with increasing aflatoxin formation [4]. The metabolomic studies also demonstrated that the lack of aflatoxin formation in a known aflatoxin inhibitory medium (peptone) was accompanied with suppressed fatty acid synthesis and reduced tricarboxylic acid (TCA) cycle intermediates, and increased pentose phosphate pathway products [5]. The accumulating NADPH pool, derived primarily from the pentose phosphate pathway, was suggested to suppress aflatoxin synthesis by directing the acyl-CoA into lipid synthesis, rather than polyketide biosynthesis [6,7].

In addition to a requirement for adequate acyl-CoA pools to synthesize aflatoxin, several groups have proposed that oxidative stress is a prerequisite for aflatoxin biosynthesis in Aspergillus parasiticus [8-10]. This observation is tied in with the hypothesis that aflatoxin is a secondary defense system protecting the fungus from excess ROS [11]. Supporting these proposals are studies showing that compounds which altered oxidative stress in A. flavus or A. parasiticus also affected aflatoxin production. For example, the pro-oxidants cumene, hydroperoxide, and hydrogen peroxide promoted aflatoxin biosynthesis in A. flavus [4], and epoxides stimulated aflatoxin formation by increasing the lipid peroxidation in A. flavus and A. parasiticus [12]. Conversely, antioxidants, such as ethylene, alleviated the oxidative stress and changed the glutathione redox state in A. flavus, which resulted in inhibiting aflatoxin biosynthesis [13]. Lentinula edodes $\beta$-glucan significantly reduced aflatoxin formation in A. parasiticus by stimulating antioxidant enzyme activity, and the activation of antioxidant response-related transcription factors, which correlated with a delay of aflatoxin genes expression [14]. Piperine inhibited aflatoxin production in A. flavus concurrently with positive regulation of genes belonging to superoxide dismutase and catalase families, as well as genes encoding the basic leucine zipper (bZIP) transcription factors AtfA, AtfB, and Ap-1 [15]. These bZIP transcription factors and MsnA are thought to participate in a regulatory network that mediates both the oxidative stress and aflatoxin pathways in A. parasiticus [11].

Gallic acid (GA), a constituent in the pellicle of Tulare walnut, has shown potent inhibitory activity toward aflatoxin biosynthesis [16], but the mechanism of GA inhibition of aflatoxin formation has not been studied. We present here our finding that GA significantly inhibited the expression of the $\operatorname{far} B$ gene, which controls the activity of peroxisomal fatty acid $\beta$-oxidation [17], and of the carbon repression regulator encoding gene, $c r e A$, which has recently been found involved in aflatoxin synthesis [18]. Simultaneously, the expression of almost all assigned genes in the aflatoxin biosynthesis cluster was significantly downregulated by $0.8 \%(w / v)$ GA treatment. Our work provides insights into cellular mechanisms underlying oxidative stress responses contributing to aflatoxin biosynthesis in A. flavus.

\section{Results}

\subsection{Effect of GA on Aflatoxin Biosynthesis and Growth in A. flavus}

Treatment of A. flavus NRRL3357 spores with different concentrations $(0,0.2 \%, 0.5 \%, 0.8 \%$, and $1 \%$, $w / v$ : Weight/volume) of GA showed that GA inhibited aflatoxin $\mathrm{B}_{1}$ synthesis in a dose-dependent manner (Figure 1). Aflatoxin $B_{1}$ production was significantly inhibited when the GA concentration was $0.5 \%(w / v)$, and was totally inhibited with greater than $0.8 \%(w / v)$ GA in the medium. Aflatoxin reduction was positively correlated with a decrease in A. flavus colony diameter (Figure 2A,B), with the maximum inhibition rate of $24 \%$ in the $1 \%(w / v)$ treated samples at the 3rd-day cultivation (Table S1). However, when A. flavus was inoculated into liquid PDB medium, mycelial mass increased in the $1 \%$ $(w / v)$ GA treated samples compared with the untreated samples (Figure 2C). 


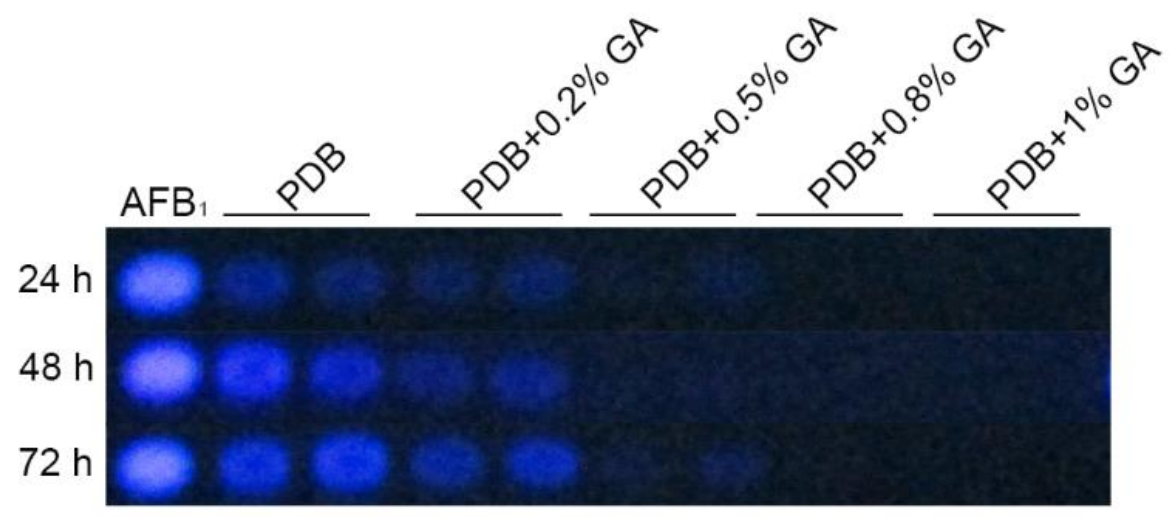

Figure 1. Gallic acid (GA) inhibits aflatoxin biosynthesis in Aspergillus flavus in a dosedependent manner.

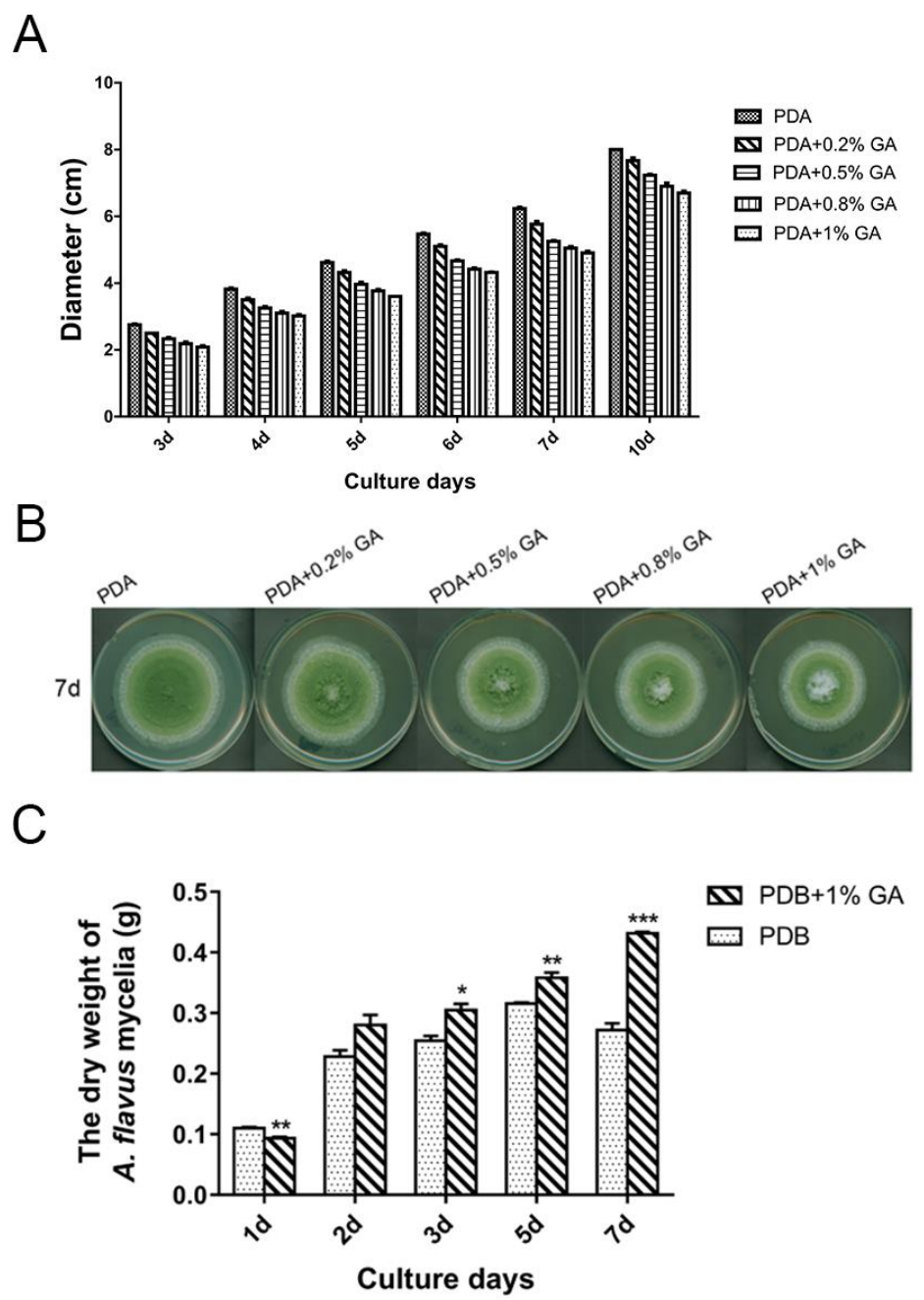

Figure 2. GA affects A. flavus growth. (A) $10^{3}$ spores were inoculated on PDA medium with different concentrations $(w / v)$ of GA and cultured at $30^{\circ} \mathrm{C}$, the diameters were measured on different culture days. (B) The photo of the samples on the 7th day cultivation. (C) $10^{7}$ spores were inoculated into $30 \mathrm{~mL}$ PDB with or without $1 \%(w / v)$ GA and cultured at $200 \mathrm{rpm}, 30{ }^{\circ} \mathrm{C}$ for different days, then the mycelia were collected and measured. Each treatment has three replicates, ${ }^{*}: p<0.05,{ }^{* *}: p<0.01,{ }^{* * *}: p<0.001$. 
A sample of $10^{7}$ spores was inoculated into $30 \mathrm{~mL}$ PDB with different concentration $(0,0.2 \%, 0.5 \%$, $0.8 \%, 1 \%, w / v)$ of GA, cultured at $30{ }^{\circ} \mathrm{C}, 200 \mathrm{rpm}$. Next, $200 \mu \mathrm{L}$ culture medium were taken out at $24 \mathrm{~h}$, $48 \mathrm{~h}$, and $72 \mathrm{~h}$, respectively, for TLC analysis, $\mathrm{AFB}_{1}$ : Aflatoxin $\mathrm{B}_{1}$ standard from Sigma. These were 0.2\% GA: $0.2 \%(w / v)$ GA, $0.5 \%$ GA: $0.5 \%(w / v)$ GA, $0.8 \%$ GA: $0.8 \%(w / v)$ GA, $1 \%$ GA: $1 \%(w / v)$ GA. $w / v$ : Weight/volume, such as $0.3 \mathrm{~g}$ GA add into $30 \mathrm{~mL}$ PDB medium will make a PDB $+1 \%(w / v)$ GA.

\subsection{Transcriptomic Profiles of A. flavus Responding to GA}

In order to gain insight into the mechanism by which GA inhibits aflatoxin synthesis, RNA was extracted from $24 \mathrm{~h}$ cultures treated with either $0.2 \%(w / v) \mathrm{GA}$ (partly inhibits aflatoxin $\mathrm{B}_{1}$ formation) or $0.8 \%(w / v)$ GA (totally inhibits aflatoxin $B_{1}$ formation) for RNA-Seq analysis. Table S2 summarizes the RNA-Seq data. The FPKM [19] value had been applied to quantify the level of each genes' expression, and the count number of each gene from the three sequenced samples were analyzed by DEseq software [20] for genes' different expression analysis. The genes with $\mid \log 2$ Ratio $\mid \geq 1$ and $q<0.05$ were considered as significantly differentially expressed and listed in Table S3. In total, 535 genes were significantly differentially transcribed between $0.2 \%(w / v)$ GA treated and untreated $A$. flavus samples, and 2040 significantly differentially expressed genes were found in $0.8 \%(w / v)$ GA treated compared with untreated A. flavus samples (Table 1). In addition, 361 shared genes were found in these two sets (Figure 3, Table S3).

Table 1. Summary of the significantly differentially expressed genes among the three samples.

\begin{tabular}{ccc}
\hline Sample Name & P02_P & P08_P \\
\hline Up & 271 & 764 \\
Down & 264 & 1276 \\
Total & 535 & 2040 \\
\hline
\end{tabular}

P02_P: $0.2 \%(w / v)$ GA treated samples (P02) compared with untreated samples (P), P08_P: 0.8\% $(w / v)$ GA treated samples (P08) compared with untreated samples (P). Up/Down: Genes' expression was significantly upregulated/downregulated in the samples before the dash, Total: All the significantly differentially expressed genes between the compared samples.

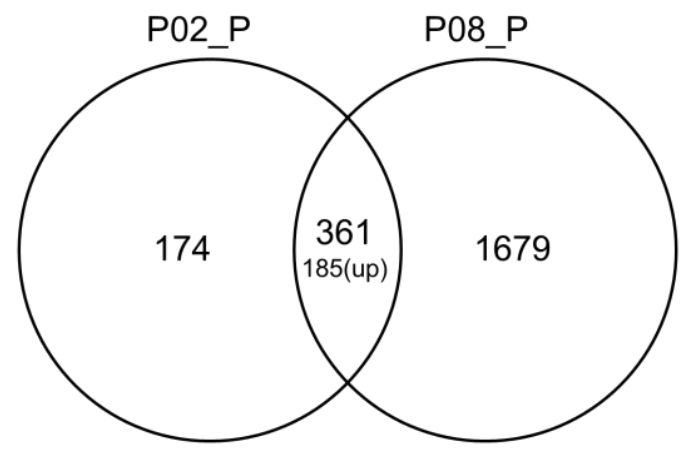

Figure 3. Venn diagram of the significantly differentially expressed genes. In total, 361 genes were shared in these two sets, of which 185 were upregulated. P02_P: Significantly differentially expressed genes between $0.2 \%(w / v)$ gallic acid-treated and untreated $A$. flavus samples. P08_P: Significantly differentially expressed genes between $0.8 \%(w / v)$ gallic acid-treated and untreated A. flavus samples.

\subsection{Effect of $G A$ on the Expression of Genes in A. flavus Secondary Metabolism Clusters}

There are 56 predicted secondary metabolism gene clusters in A. flavus [21,22], most of which contain a gene encoding for a 'backbone' enzyme (e.g., PKS, NRPS, DMATs, terpene, etc) essential for their respective secondary metabolite biosynthesis [22]. The effect of GA on the A. flavus 56 secondary metabolism clusters activity was analyzed based on the 'backbone' genes expression in our RNA-Seq data, and the data showed that there were 16 secondary metabolism clusters significantly affected by GA treatment (Table S4). The cluster \#54, responsible for the aflatoxin biosynthesis, was one of 
these 16 clusters, and almost all the assigned genes (except the regulatory genes aflR and aflS [23]) expression were significantly downregulated in the $0.8 \%(w / v)$ GA treated samples compared with the untreated samples (Figure 4, Table S3). These data are consistent with the $0.8 \%(w / v)$ GA totally inhibiting aflatoxin formation in A. flavus (Figure 1).

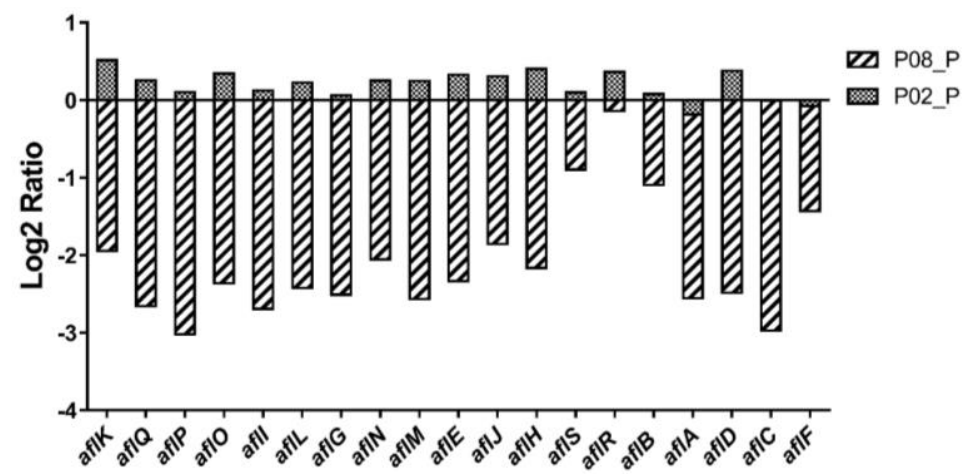

Figure 4. Effect of GA on the expression of the aflatoxin assigned genes in A. flavus. P: Untreated A. flavus samples, P02: 0.2\% (w/v) GA treated A. flavus samples, P08: 0.8\% (w/v) GA treated A. flavus samples. P02_P Ratio: The mean value of the count number of each gene in P02/in P. P08_P Ratio: The mean value of the count number of each gene in $\mathrm{P} 08 /$ in $\mathrm{P}$.

2.4. Expression Changes of the Developmental Regulatory Genes and the Primary Metabolic Genes in A. flavus in Response to GA

Because the genes encoding aflatoxin transcription factors aflR and aflS were not significantly affected by GA (Table S3), we next examined the RNA-seq for other clues as to why aflatoxin biosynthesis and gene expression were down regulated. We first looked at transcriptional regulators of aflatoxin. The Velvet Complex heterotrimer is a critical transcriptional complex required for secondary metabolism and fungal development in Aspergillus spp. [24], including A. flavus [25]. However, in our data, the expression of all three members, veA, velB, and lae $A$ were not significantly different in the GA-treated $A$. flavus samples compared with the untreated $A$. flavus samples. We also observed that $n s d C$ encoding a $\mathrm{C}_{2} \mathrm{H}_{2}$ zinc finger-type DNA-binding protein, which is required for normal sclerotia formation and aflatoxin biosynthesis in A. flavus [26], was upregulated (Table 2) and thus not a likely cause of loss of aflatoxin production by GA.

Carbon utilization pathways have also been associated with aflatoxin biosynthesis. In our RNA-Seq data, most of the putative genes responsible for the pentose phosphate pathway were upregulated by GA treatment, such as AFLA_086620, AFLA_080390, and AFLA_036840 (Table 2) encoding proteins homologous to Zwf1, Sol3, and Gnd1 in Candida albicans, respectively [27]. Pentose phosphate pathway activity has been linked to decreased aflatoxin synthesis in a previous study [5] and thus supports a possible role of this pathway in gallic acid repression of aflatoxin production.

Fatty acids and $\beta$-oxidation have been largely shown to promote aflatoxin biosynthesis [3,28]. The most striking finding from the RNA-seq data was the large number of peroxisome and fatty acid $\beta$-oxidation-related genes (Table S5) which were significantly and primarily down regulated by GA treatment based on the GO analysis (Table S6). These genes included the peroxisomal $\beta$-oxidation multifunctional enzyme encoding gene, fox $A$ [29], and acetyl-carnitine transferase encoding gene, acuJ [30]. The fatty acid metabolism regulatory transcription factor gene, farB (AFLA_012010), was also downregulated. FarB has been reported as positively affecting aflatoxin biosynthesis in $A$. flavus via regulating the expression of the peroxisomal fatty acid $\beta$-oxidation-related genes pexK, fox $A$, and $a c u J$ [17].

Finally, we noted that the carbon catabolite repression gene, cre $A$ [31], decreased with the increasing concentration of GA and was significantly downregulated in the $0.8 \%(w / v)$ GA-treated samples compared with the untreated samples (Table 2). CreA regulates gene expression, either directly by binding to the consensus binding sites (5'-SYGGRG-3') in the promoter of the target genes [32], 
or through transcriptional cascades. This consensus binding site is found in 14 out of the 19 aflatoxin gene promoter regions (Table 3), and because expression of these genes (except aflR and aflS) was significantly downregulated by GA treatment, it appeared likely that GA regulation of $c r e A$ was also contributing to the reduction of aflatoxin synthesis. Indeed we found that all 19 assigned aflatoxin genes were significantly downregulated in two independent $\Delta c r e A$ mutants compared with wild type (WT) (Figure 5). These results were consistent with the loss of aflatoxin synthesis in the deletion of creA in another strain of A. flavus, CA14 [18].

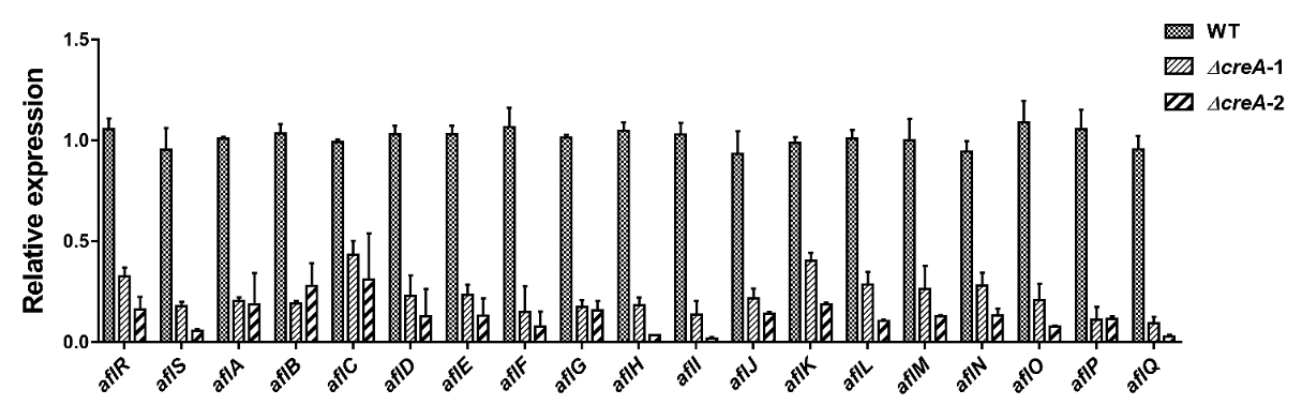

Figure 5. Expression ratios of the aflatoxin biosynthesis-assigned genes in the $\triangle c r e A$ mutants compared to wild type WT(TJW149.27). A total of $10^{7}$ spores of WT, $\Delta c r e A-1$, and $\Delta c r e A-2$ were inoculated into $30 \mathrm{~mL}$ PDB medium, and cultured at $200 \mathrm{rpm}, 30^{\circ} \mathrm{C}$ for 3 days, the mycelia was collected for RNA extraction, then the RNA was reverse transcript into cDNA for qRT-PCR analysis. The primers for the qRT-PCR can be found in Table S7. The expression of each gene in the WT was normalized as 1.0, each sample has three replicates, and the error bars indicate the standard error of the mean. 
Table 2. Effect of gallic acid (GA) treatment on the expression of the transcription factor genes and primary metabolites related genes in Aspergillus flavus.

\begin{tabular}{|c|c|c|c|c|c|c|c|c|}
\hline \multirow[b]{2}{*}{ Gene Name } & \multicolumn{4}{|c|}{ P02-P ${ }^{a}$} & \multicolumn{4}{|c|}{ P08-P b } \\
\hline & $\log 2$ Ratio $^{c}$ & $p$ Value & Up/Down & Significant ${ }^{\mathrm{e}}$ & Log2 Ratio $d$ & $p$ Value & Up/Down & Significant \\
\hline $\begin{array}{c}v e A \\
\text { (AFLA_066460) }\end{array}$ & -0.4470 & 0.6546 & down & no & -0.3915 & $2.64 \times 10^{-1}$ & down & no \\
\hline $\begin{array}{c}\text { laeA } \\
\text { (AFLA_033290) }\end{array}$ & -0.2987 & 0.8134 & down & no & -0.6969 & $1.71 \times 10^{-2}$ & down & no \\
\hline $\begin{array}{c}\text { velB } \\
\text { (AFLA_081490) }\end{array}$ & 0.9331 & 0.1439 & up & no & 0.0635 & $9.35 \times 10^{-1}$ & up & no \\
\hline $\begin{array}{c}b r l A \\
\text { (AFLA_082850) }\end{array}$ & -2.5580 & 0.0010 & down & yes & -2.3343 & $9.88 \times 10^{-6}$ & down & yes \\
\hline $\begin{array}{c}\text { NsdC } \\
\text { (AFLA_131330) }\end{array}$ & 1.6888 & 0.0091 & up & yes & 1.1464 & $3.45 \times 10^{-5}$ & up & yes \\
\hline $\begin{array}{c}c r e A \\
\text { (AFLA_134680) }\end{array}$ & -0.3367 & 0.8277 & down & no & -1.1486 & $9.15 \times 10^{-8}$ & down & yes \\
\hline $\begin{array}{c}f a r B \\
\text { (AFLA_012010) }\end{array}$ & -0.7799 & 0.4354 & down & no & -1.5190 & $4.81 \times 10^{-5}$ & down & yes \\
\hline $\begin{array}{c}\text { foxA } \\
\text { (AFLA_041590) }\end{array}$ & -0.5139 & 0.6420 & down & no & -1.1589 & $1.71 \times 10^{-5}$ & down & yes \\
\hline $\begin{array}{c}\text { AcuJ } \\
\text { (AFLA_135240) }\end{array}$ & -0.8148 & 0.2928 & down & no & -1.2998 & $1.85 \times 10^{-5}$ & down & yes \\
\hline $\begin{array}{c}\text { PexK } \\
\text { (AFLA_036410) }\end{array}$ & -0.7519 & 0.3792 & down & no & -0.8524 & $2.72 \times 10^{-4}$ & down & no \\
\hline $\begin{array}{c}z w f 1 \\
\text { (AFLA_086620) }\end{array}$ & 0.6412 & 0.4931 & up & no & 0.7590 & $6.7 \times 10^{-3}$ & up & no \\
\hline $\begin{array}{c}\text { sol3 } \\
\text { (AFLA_080390) }\end{array}$ & 0.2110 & 0.8837 & up & no & 1.0991 & $1.0 \times 10^{-4}$ & up & yes \\
\hline $\begin{array}{c}\text { gnd1 } \\
\text { (AFLA_036840) }\end{array}$ & 0.3718 & 0.7936 & up & no & 0.9072 & $1.3 \times 10^{-3}$ & up & no \\
\hline
\end{tabular}

a: $0.2 \%(w / v)$ GA-treated samples (P02) compared with the untreated samples $(\mathrm{P}){ }^{\mathrm{b}}: 0.8 \%(w / v)$ GA-treated samples (P08) compared with the untreated samples $(\mathrm{P}) .^{\mathrm{c}}:$ The mean value of the count number of each gene in P02/in P. ${ }^{\mathrm{d}}$ : The mean value of the count number of each gene in P08/in P. ${ }^{\mathrm{e}}$ : The genes with $\mid$ Log2 ratio $\mid \geq 1$ and $p$ value $<0.05$ were considered as significantly differentially expressed, described as 'yes', otherwise described as 'no'. 
Table 3. Presence of the CreA consensus binding motif (5'-SYGGRG-3') in the aflatoxin biosynthesis genes promotor region.

\begin{tabular}{|c|c|c|c|}
\hline Gene Name & $\begin{array}{l}\text { CreA Binding Motif } \\
\left(5^{\prime}-S Y G G R G-3^{\prime}\right)^{a}\end{array}$ & $\begin{array}{l}\text { Position Relative to } \\
\text { Start Codon }\end{array}$ & Description \\
\hline AFLA_139190 & GTGGAG & -361 & aflK/vbs/VERB synthase \\
\hline AFLA_139200 & CTGGAG & -795 & aflQ/ordA/ord-1/oxidoreductase/cytochrome $\mathrm{P} 450$ monooxigenase \\
\hline AFLA_139210 & No motif found & & aflP/omt $A$ /omt-1/O-methyltransferase $\mathrm{A}$ \\
\hline AFLA_139220 & GTGGGG & -1201 & aflO/omtB/dmtA/O-methyltransferase B \\
\hline AFLA_139230 & CTGGGG/CCGGAG/GCGGAG & $-355 /-398 /-301$ & aflI / avfA/cytochrome P450 monooxygenase \\
\hline AFLA_139250 & CTGGGG & -238 & aflL/verB/desaturase/P450 monooxygenase \\
\hline AFLA_139260 & CTGGGG/GCGGAG & $-365 /-810$ & aflG/avnA/ord-1/cytochrome P450 monooxygenase \\
\hline AFLA_139280 & No motif found & & aflN/ver $A /$ monooxygenase \\
\hline AFLA_139300 & No motif found & & aflM/ver-1/dehydrogenase/ketoreductase \\
\hline AFLA_139310 & CTGGGG/GCGGAG & $-482 /-617$ & aflE/norA/aad/adh-2/NOR reductase/dehydrogenase \\
\hline AFLA_139320 & CCGGGG/CTGGGG & $-387 /-299$ & aflJ/estA/esterase \\
\hline AFLA_139330 & GTGGGG/GCGGAG & $-488 /-58$ & aflH/adhA/short chain alcohol dehydrogenase \\
\hline AFLA_139340 & GTGGAG/CCGGGG & $-737 /-762$ & aflS/pathway regulator \\
\hline AFLA_139360 & GTGGGG/CCGGAG/CTGGAG & $-369 /-895 /-276$ & aflR/apa-2/afl-2/transcription activator \\
\hline AFLA_139370 & CTGGAG/CTGGGG & $-450 /-819$ & aflB / fas- 1 / fatty acid synthase beta subunit \\
\hline AFLA_139380 & GTGGAG & -116 & aflA/fas-2/hexA/fatty acid synthase alpha subunit \\
\hline AFLA_139390 & No motif found & & aflD/nor-1/reductase \\
\hline AFLA_139410 & GTGGCG & -763 & aflC/pksA/pksL1/polyketide synthase \\
\hline AFLA_139440 & No motif found & & aflF/norB/dehydrogenase \\
\hline
\end{tabular}




\subsection{Effect of GA on Oxidative Stress Genes and the Antioxidant Enzymatic Activities}

In A. flavus, there are several oxidative stress-related transcription factors that mediate oxidative stress and aflatoxin formation, and among these AtfA, AtfB, Ap-1, and MsnA have been characterized [33-36]. The expression of the genes encoding these transcription factors did not show significant difference in the GA-treated samples compared with the untreated samples. However, we found some of the enzymatic genes regulated by these transcription factors were differentially regulated, including the genes encoding the antioxidant enzymes catalase (AFLA_056170, AFLA_122110, and AFLA_090690) and superoxide dismutase (SOD, AFLA_099000, and AFLA_033420), which were slightly upregulated in the $0.8 \%(w / v)$ GA-treated samples compared with the untreated samples. Additionally, genes encoding the glutathione S-transferase and the thioredoxin system proteins presented significantly higher expression levels in the $0.8 \%(w / v)$ GA-treated samples compared with the untreated samples (Table 4). Oxylipin synthesis is associated with oxidative processes and aflatoxin biosynthesis and, as shown in Table 4, the $p p o C$ gene encoding for oxylipin biosynthesis [37] and the GPCRs genes $g p r C$, gprK, and gprM-implicated in oxylipin perception [38] — were significantly inhibited by at least one GA treatment.

To gain more information on this possible linkage of GA with oxidative processes, the activities of catalase and SOD and the level of Malondialdehyde (MDA, as a marker of lipid oxidation) were measured in the $0.2 \%(w / v)$ and $0.8 \%(w / v)$ GA-treated and untreated A. flavus samples with $24 \mathrm{~h}$ cultivation. Results, shown in Figure 6, demonstrated that the MDA content was decreased by GA treatment (Figure 6A), and the activities of catalase and SOD were also inhibited in the GA treated samples compared with the untreated samples (Figure 6B,C), despite a slight increase in gene expression. These results and the expression of the antioxidant genes indicate that GA may balance oxidative stress homeostasis in A. flavus via activating the glutathione- and thioredoxin-dependent antioxidant system, rather than through catalase and SOD activity.
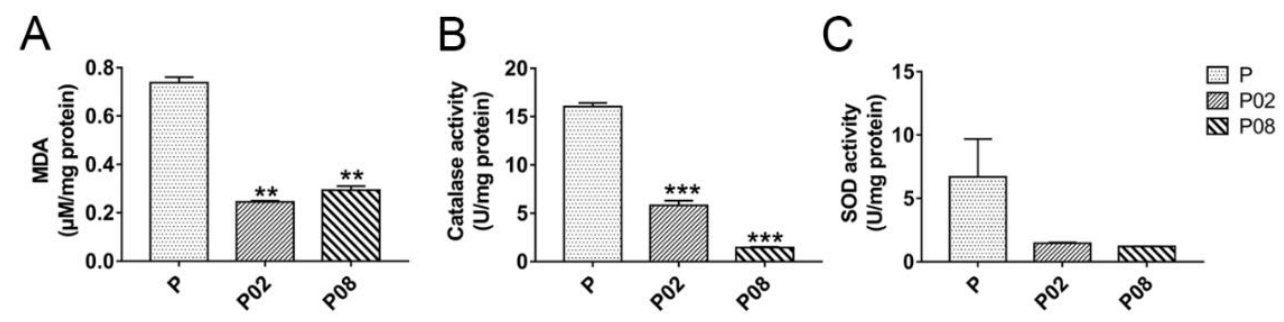

Figure 6. Effect of GA on lipid oxidant (A) and antioxidant enzymes activities (B,C) in A. flavus. P: Untreated A. flavus samples, P02: 0.2\% (w/v) GA-treated A. flavus samples, P08: 0.8\% (w/v) GA-treated A. flavus samples. ${ }^{* *}: p<0.01,{ }^{* * *}: p<0.001$. MDA $=$ Malondialdehyde, SOD $=$ super oxide dismutase. 
Table 4. Effect of GA on the expression of the antioxidant-related genes in A. flavus.

\begin{tabular}{|c|c|c|c|c|c|c|c|c|}
\hline \multirow[b]{2}{*}{ Gene Name } & \multicolumn{4}{|c|}{ P02-P ${ }^{a}$} & \multicolumn{4}{|c|}{$\mathrm{P}^{08-\mathrm{P}^{\mathrm{b}}}$} \\
\hline & Log2 Ratio ${ }^{c}$ & $p$ Value & Up/Down & Significant ${ }^{\mathrm{e}}$ & Lpog2 Ratio ${ }^{d}$ & $p$ Value & Up/Down & Significant ${ }^{\mathrm{e}}$ \\
\hline $\begin{array}{c}\text { ppoC } \\
\text { (AFLA_030430) }\end{array}$ & -2.0268 & 0.0003 & down & yes & -1.4056 & $7.25 \times 10^{-2}$ & down & no \\
\hline $\begin{array}{c}g p r C \\
\text { (AFLA_074150) }\end{array}$ & -1.4207 & 0.0703 & down & no & -1.5934 & $4.14 \times 10^{-6}$ & down & yes \\
\hline $\begin{array}{c}g \bar{p} r K \\
\text { (AFLA_009790) }\end{array}$ & -1.2764 & 0.3936 & down & no & -2.1266 & $9.73 \times 10^{-4}$ & down & yes \\
\hline $\begin{array}{c}\text { gprM } \\
\text { (AFLA_075000) }\end{array}$ & -2.0079 & 0.0069 & down & yes & -1.4338 & $3.74 \times 10^{-2}$ & down & yes \\
\hline $\begin{array}{l}\text { glutathione S-transferase } \\
\text { (AFLA_016400) }\end{array}$ & 0.1570 & 0.9701 & up & no & 1.1480 & $1.20 \times 10^{-4}$ & up & yes \\
\hline $\begin{array}{l}\text { glutathione S-transferase } \\
\text { (AFLA_023740) }\end{array}$ & 0.4667 & 0.6766 & up & no & 1.2355 & $2.13 \times 10^{-3}$ & up & yes \\
\hline $\begin{array}{l}\text { glutathione S-transferase } \\
\text { (AFLA_087240) }\end{array}$ & 0.8037 & 0.3272 & up & no & 2.0188 & $1.07 \times 10^{-12}$ & up & yes \\
\hline $\begin{array}{l}\text { AhpC/TSA family thioredoxin peroxidase } \\
\text { (AFLA_097940) }\end{array}$ & 1.1384 & 0.0655 & up & no & 1.2150 & $4.41 \times 10^{-5}$ & up & yes \\
\hline $\begin{array}{l}\text { thioredoxin reductase Trr1/Trr2 } \\
\text { (AFLA_051770) }\end{array}$ & 0.8950 & 0.2535 & up & no & 1.0196 & $3.79 \times 10^{-2}$ & up & yes \\
\hline
\end{tabular}

a: $0.2 \%(w / v)$ GA-treated samples (P02) compared with the untreated samples (P). ${ }^{\mathrm{b}}: 0.8 \%(w / v)$ GA-treated samples (P08) compared with the untreated samples (P). ${ }^{\mathrm{c}}$ : The mean value of the count number of each gene in P02/in P. ${ }^{\mathrm{d}}$ : The mean value of the count number of each gene in P08/in $\mathrm{P}$. ${ }^{\mathrm{e}}$ : The genes with $\mid \log 2$ ratio $\mid \geq 1$ and $p$ value $<0.05$ were considered as significantly differentially expressed, described as 'yes', otherwise described as 'no'. 


\section{Discussion}

Upon finding that GA was effective in suppressing aflatoxin synthesis, Mahoney and Molyneux [16] suggested the mechanism might be through GA control of the fatty acid synthases (aflA, aflB) or polyketide synthase $(a f l C)$ required for generation of norsolorinic acid, the first visible and stable intermediate in the aflatoxin synthesis pathway [23], which accumulates in peroxisome [3]. In this study, we not only observe down-regulation of these genes, but also identify the cellular pathways which may be affecting regulation of these genes and aflatoxin synthesis in general. We demonstrated that GA inhibited aflatoxin biosynthesis in A. flavus in a dose-dependent manner, where aflatoxin formation was partly inhibited by $0.2 \%(w / v)$ GA treatment and totally inhibited by more than $0.8 \%$ $(w / v)$ GA treatment. To find out the genes mediating GA and aflatoxin biosynthesis in A. flavus, the transcriptomic profile of the $0,0.2 \%$, and $0.8 \%(w / v)$ GA-treated A. flavus samples was obtained based on the RNA-Seq technology. Taken together, the transcriptional profiling results suggested GA could be suppressing aflatoxin synthesis through several cellular pathways that have already been implicated in aflatoxin regulation: One inhibitory (pentose phosphate pathway) and two stimulatory routes (FarB mediated $\beta$-oxidation and CreA activity). The expression changes of those genes in $0.2 \%(w / v)$ GA treatment is consistent with the partly inhibited aflatoxin formation in this treatment. Both the pentose phosphate pathway and $\beta$-oxidation pathway are active in the peroxisome, the site of the initial steps of aflatoxin biosynthesis [3]. Despite GA's role as an antioxidant, the RNA-seq and physiological testing (Figure 6) were less clear on the role of antioxidant pathways in suppressing aflatoxin synthesis, although potential involvement of the glutathione- and thioredoxin-dependent antioxidant systems will be a future avenue to address. We also note that the antioxidant activity of the gallic acid molecule itself could be a contributing factor [39].

Aflatoxin molecular formation needs more than 23 enzymatic reactions [23] and at least 10 NADPHs [40], however, there is a competition for NADPH in acetyl-CoA incorporation into lipid synthesis, rather than into polyketides like aflatoxin [6]. In the toxin-supporting medium (Glucose-mineral salts medium, GMS), diminished NADPH generating capacity indicated that depressed NADPH/NADP ratios favor aflatoxin biosynthesis [41]. The two dehydrogenases (Zwf1 and Gnd1) in the oxidative branch of the pentose phosphate pathway, the main source of NADPH in the cell, are located in peroxisomes in Candida albicans [27]. The genes AFLA_086620 and AFLA_036840, encoding the homologous Zwf1 and Gnd1 proteins, respectively, were upregulated by GA treatment (Table 2), which indicated that GA treatment might regulate $A$. flavus intracellular NADPH pools and promote acyl-CoA incorporation into lipid synthesis, rather than polyketide production.

Acetyl-CoA is produced from the oxidative decarboxylation of pyruvate and fatty acid $\beta$-oxidation [40], and fatty acid $\beta$-oxidation is a fundamental contributor to polyketide mycotoxin (aflatoxin and sterigmatocystin) formation [3]. The fatty acid transcription factor FarB-which activates peroxisomal $\beta$-oxidation genes-has been shown to positively regulate aflatoxin production in A. flavus [17]. In our RNA-Seq data, most of the genes involved in fatty acid $\beta$-oxidation, including farB, were downregulated by GA treatment (Table S5). The transcript of $f a r B$, foxA (encoding the peroxisomal $\beta$-oxidation multifunctional enzyme), and $a c u J$ (encoding carnitine acetyltransferase), were significantly decreased in the $0.8 \%(w / v)$ GA-treated samples compared to the untreated samples (Table 2). Suppression of the peroxisomal $\beta$-oxidation pathway genes by GA treatment would be expected to reduce acyl-CoA pools and inhibit aflatoxin formation through lack of precursors.

Aflatoxin biosynthesis is also closely associated with carbohydrate catabolism [41]. For example, glucose, sucrose, and fructose induced aflatoxin formation, while peptone and lactose did not support aflatoxin production [28,42]. Abdollahi et al. [28] suggested that the aflatoxin formation induced by these carbon sources was as a feedback regulation of the elevated energy state which was caused by the utilization of a readily-metabolizable carbohydrate. Microorganisms prefer utilizing the most favored carbon source with the mechanism of carbon repression, and the transcription factor CreA is a well-known as carbon repression regulator in Aspergillus [31]. In Aspergillus nidulans, CreA can regulate carbon utilization genes via directly binding to the consensus sequence $5^{\prime}$-SYGGRG-3' in 
the promoter of these genes [32], and is critical for normal growth on carbon, nitrogen, and lipid sources [43]. The CreA consensus binding sites have been found in the promoter regions of 14 assigned aflatoxin genes (Table 3), and the expression of almost all the aflatoxin genes (except the regulator genes aflR and aflS) and the creA gene, AFLA_134680, were significantly suppressed by the $0.8 \%(w / v)$ GA treatment (Figure 4, Table 2). To confirm the hypothesis that CreA was involved in aflatoxin gene regulation, we deleted creA in $A$. flavus and the $\triangle c r e A$ mutants were unable to produce the mycotoxin. The qRT-PCR result showed that the expression of the aflatoxin genes were significantly down regulated in the $\triangle c r e A$ mutants compared to WT, which is consistent with an identical role for this protein in aflatoxin biosynthesis in another strain of $A$. flavus, CA14 [18]. Whether the regulation is direct via CreA binding of individual afl genes or indirect is still to be determined. In A. flavus, GprC was considered as a carbon sensing receptor [38] which may mediate the expression of carbon utilization genes. As the GprC encoding gene was significantly inhibited by $0.8 \%(w / v)$ GA treatment, we propose that GA may depress creA expression through GprC signaling. Taking these results together, we suggest that GA inhibits aflatoxin biosynthesis in A. flavus via modulating the expression of the FarB and CreA pathways, a hypothetical mechanism proposed in Figure 7.

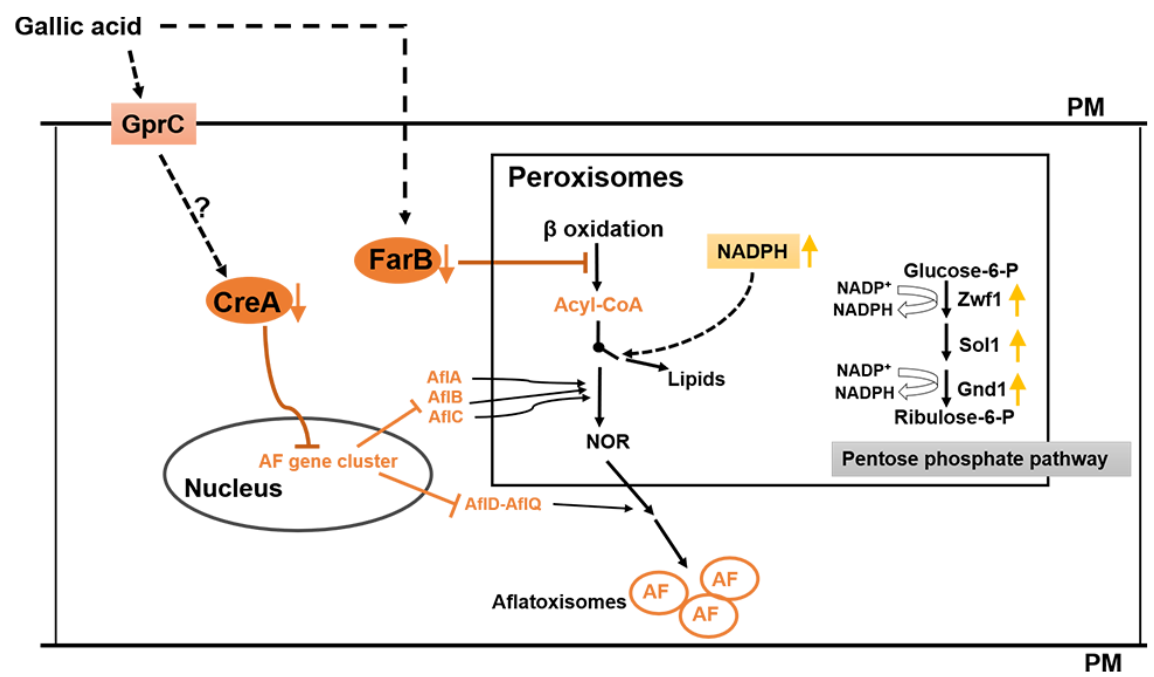

Figure 7. Hypothetical mechanism of gallic acid (GA) inhibition of aflatoxin biosynthesis in A. flavus. GA inhibits (i) the expression of $c r e A$, which leads to the downregulation of the aflatoxin (AF) cluster genes, simultaneously GA (ii) reduces the peroxisomal fatty acids $\beta$-oxidation level by diminishing the expression of $f a r B$, resulting in decreasing the aflatoxin precursor acyl-CoA pools, and (iii) increasing the NADPH level via the pentose phosphate pathway, which favors lipid synthesis over aflatoxin biosynthesis in A. flavus. PM: Plasma membrane. The orange downward arrows indicate the expression of the genes that were significantly downregulated by GA treatment, the yellow upward arrows indicate the higher activity of the pentose phosphate pathway, which leads to increasing NADPH pools. Dotted lines indicate possible connecting pathways and solid lines indicate known pathways.

\section{Materials and Methods}

\subsection{Fungal Strain and Culture Conditions}

Aspergillus flavus NRRL3357 [44], TJES20.1 ( $\Delta k u 70, \Delta \operatorname{argB::A.~fumigatus~pyrG,~pyrG-)~[45],~}$ and TJW149.27 ( $\triangle k u 70::$ A. parasiticus pyrG, pyrG-) were used in this research. A total of $10^{7} \mathrm{~A}$. flavus NRRL3357 spores were inoculated into $30 \mathrm{~mL}$ PDB (BD Difco) with different concentrations (0, 0.2\%, $0.5 \%, 0.8 \%$, and $1 \% \mathrm{w} / \mathrm{v}$ ) of GA, cultured at $30{ }^{\circ} \mathrm{C}, 200 \mathrm{rpm}$ for aflatoxin analysis or mycelia weight measurement. A total of $10^{3}$ spores were inoculated on PDA (BD Difco) medium with different concentrations $(w / v)$ of GA and cultured at $30^{\circ} \mathrm{C}$ for diameter determination. TJES20.1 was used for deleting creA gene in A. flavus, and TJW149.27 was used as control for creA mutants. 


\subsection{Aflatoxin Analysis and Measuring the A. flavus Colony Diameters and Mycelia Weights}

Aflatoxin was extracted from $200 \mu \mathrm{L}$ culture medium and analyzed by modified thin-layer chromatography (TLC) [46]. A total of $10^{3}$ A. flavus spores were point-inoculated on PDA medium with different concentrations of GA, the plates were cultured at $30^{\circ} \mathrm{C}$ incubator, and the diameters were measured on different culture days. To investigate the effect of GA on A. flavus mycelia growth, $10^{7}$ A. flavus spores were inoculated into $30 \mathrm{~mL}$ PDB medium with or without $1 \%(w / v)$ GA, and cultured at $30^{\circ} \mathrm{C}, 200 \mathrm{rpm}$. The mycelia were collected by using vacuum filtration and measured by analytical balance $(0.0001 \mathrm{~g})$ after drying in the oven.

\subsection{RNA Extraction and cDNA Library Preparation for RNA-Seq Analysis}

Triplicate cultures of $10^{7}$ A. flavus spores were grown in PDB medium with $0,0.2 \%$, and $0.8 \%$ $(w / v) \mathrm{GA}$, respectively, at $30^{\circ} \mathrm{C}, 200 \mathrm{rpm}$, harvested after $24 \mathrm{~h}$, and ground in a mortar and pestle under liquid nitrogen. TRIzol reagent (Invitrogen, Carlsbad, CA, USA) was used to extract total RNA from ground mycelia, according to the manufacturer's instructions. Library construction and RNA quality analysis for all nine samples were conducted by Annoroad (Beijing, China). The Agilent 2100 bioanalyzer with Agilent RNA 6000 Nano Kit (Agilent Technologies, Santa Clara, CA, USA) was used to assess the integrity and purity of the RNA samples. All samples had an RNA Integrity Number (RIN) with more than 8.0. The cDNA library construction was conducted as follows: The mRNA was purified by using Oligo (dT)-attached magnetic beads and fragmented into small pieces by Fragmentation Buffer. The fragmented mRNA was copied into first strand cDNA using random hexamer primers, then the dNTPs, RNase $\mathrm{H}$, and DNA polymerase I were added into the reactions to get the second strand cDNA. These cDNA fragments were purified with QIAQuick PCR kit and eluted with elution buffer, then these cDNA fragments were treated through an end repair process, an addition of a single ' $\mathrm{A}$ ' base, and then ligation of the sequencing adapters. Finally, the cDNA library was sequenced on the Illumina HiSeq platform.

\subsection{Data Analysis and Normalizing the Expression Levels of Genes}

After removing the reads adapters, low quality reads, and reads with more than $5 \% \mathrm{~N}$, the remaining reads were mapped to the A. flavus NRRL3357 genome (https: / / www.ncbi.nlm.nih.gov / nuccore/ AAIH00000000.2) by using TopHat v2.0.12 [47] and Bowtie2 [48] software. The Fragments per Kilobase per Million Mapped Fragments (FPKM) [19] was used to normalize the expression levels of the genes in these sequenced samples. The mean value of the count number of each gene from the three sequenced samples were analyzed by DEseq software [20] for genes' different expression analysis, the genes from each compared sample with $\mid \log 2$ Ratio $\mid \geq 1$ and $q<0.05$ were considered as significantly differentially expressed between these compared samples. GO analysis was done by Blast2GO software. The transcriptomic profile of the detectable genes in this research can be found in Table S3.

\section{5. creA Mutant Construction and qRT-PCR Analysis}

All primers used for creA mutant construction are listed in Table S7. The homologous recombination technology was used to create a creA mutant [45]. All PCR-generated flanks ranged in size around $1.5 \mathrm{~kb}, \arg B$ with its own promotor and terminator from $A$. flavus and wild type genomic DNA was used as the marker gene. The transformation construct for creA mutant was made by double joint PCR [49] and transformed into the parental strain TJES20.1 ( $\Delta k u 70, \Delta \arg B::$ Aspergillus fumigatus pyrG, pyrG-). Transformation of fungal strains was carried out according to the protocol of Szewczyk et al. [50], with some modifications that can be found in Zhao et al. [51]. The creA mutants were confirmed by PCR and qRT-PCR (Figure S1A,B), and aflatoxin synthesis of creA mutants (Figure S1C) was analyzed by TLC, the primers for qRT-PCR can be found in Table S7. A total of $10^{7}$ spores of WT, $\triangle c r e A-1$, and $\triangle c r e A-2$ were inoculated into $30 \mathrm{~mL}$ PDB medium, and cultured at $200 \mathrm{rpm}, 30^{\circ} \mathrm{C}$ for 3 
days, and the mycelia were collected for RNA extraction. RNA was extracted by Trizol (Invitrogen, Carlsbad, CA, USA) following the manufacturer's instructions. RNA quality and quantity were measured by NanoVue plus (GE Healthcare, Buckinghamshire, UK). Reverse transcription was carried out by HiScriptIIQ RT SuperMix (Vazyme, Nanjing, China) for qRT-PCR.

\subsection{Antioxidant Enzymatic Activities and the Lipid Oxidation Level Measurement}

In order to observe the impact of GA on the antioxidant system activities in A. flavus, superoxide dismutase (SOD), catalase (CAT), and the content of Malondialdehyde (MDA) were performed on $24 \mathrm{~h}$ cultures, following the same culture conditions of RNA isolation.

Around $300 \mathrm{mg}$ mycelium were suspended in $800 \mu \mathrm{L}$ PBS buffer and homogenized by Tissuelyser ${ }^{\circledR}$ (Jingxin industrial development Co., Shanghai, China). Then samples were centrifuged at 12,000 rpm for $10 \mathrm{~min}$ at $4{ }^{\circ} \mathrm{C}$, the supernatants were used for measuring the enzymes activities, MDA content, and protein concentrations. The catalase assay kit (S0051) and total superoxide dismutase assay kit with WST-8 (S0101) were used to measure the enzymes activities, the MDA content was determined using lipid peroxidation MDA assay kit (S0131), and protein concentrations were measured using an enhanced BCA protein assay kit (P0010). All these measurements were conducted according to manufacturer's instructions, and these kits were bought from Beyotime Biotechnology (Beijing, China). The enzymatic activities and MDA content were normalized according to their protein concentrations.

\subsection{Statistical Analysis}

All the wet-lab experiments were conducted in triplicate. The GraphPad Prism software (La Jolla, CA, USA) was used for statistical analysis. Statistically significant differences were determined by an unpaired Student's $t$-test with a two-tailed distribution and $p<0.05$. The error bars in all figures indicate the standard error of the mean.

Supplementary Materials: The following are available online at http:/ / www.mdpi.com/2072-6651/10/7/270/s1, Table S1: The inhibition rate and significance analysis of gallic acid on A. flavus growth. Table S2: Summary of the RNA-Seq data. Table S3: The transcriptomic profile of the detectable genes and the significantly differentially expressed genes. Table S4: The backbone genes of the 56 secondary metabolism clusters. Table S5: The genes enriched in peroxisome and fatty acid $\beta$-oxidation based on the GO analysis. Table S6: The GO data in this research. Table S7: Primers used to create creA mutants and for qRT-PCR analysis. Figure S1: Confirmation of the creA mutants and the aflatoxin formation in creA mutants.

Author Contributions: X.Z. and Z.-M.H. designed the experiments, N.P.K. supervised the data analysis, X.Z., N.P.K. and Z.-M.H. wrote the paper. X.Z. and Q.-Q.Z. performed all the experiments, J.-Y.L. contributed to the RNA extraction and other experiments. All authors read and approved the final manuscript.

Funding: This research received no external funding.

Acknowledgments: This work was supported in part by the National Natural Science Foundation of China (Grant No. 31470198), the Science and Technology Planning Project of Guangdong Province, China (Grant No. 2016B020204001), and the Science and Technology Planning Project of Guangzhou City, China (Grant No. 201510010158) to Z.M.H. and in part by support by the Food Research Institute to N.P.K.

Conflicts of Interest: The authors declare no conflict of interest.

\section{References}

1. Amaike, S.; Keller, N.P. Aspergillus flavus. Annu. Rev. Phytopathol. 2011, 49, 107-133. [CrossRef] [PubMed]

2. Nesbitt, B.F.; O’Kelly, J.; Sargeant, K.; Sheridan, A. Aspergillus flavus and turkey X disease. Toxic metabolites of Aspergillus flavus. Nature 1962, 195, 1062-1063. [CrossRef] [PubMed]

3. Maggio-Hall, L.A.; Wilson, R.A.; Keller, N.P. Fundamental contribution of $\beta$-oxidation to polyketide mycotoxin production in planta. Mol. Plant Microbe Interact. 2005, 18, 783-793. [CrossRef] [PubMed]

4. Reverberi, M.; Punelli, M.; Smith, C.A.; Zjalic, S.; Scarpari, M.; Scala, V.; Cardinali, G.; Aspite, N.; Pinzari, F.; Payne, G.A.; et al. How peroxisomes affect aflatoxin biosynthesis in Aspergillus flavus. PLoS ONE 2012, 7, e48097. [CrossRef] [PubMed] 
5. Yan, S.; Liang, Y.; Zhang, J.; Liu, C.M. Aspergillus flavus grown in peptone as the carbon source exhibits spore density- and peptone concentration-dependent aflatoxin biosynthesis. BMC Microbiol. 2012, 12, 106. [CrossRef] [PubMed]

6. Kiser, R.C.; Niehaus, W.G. Purification and kinetic characterization of mannitol-1-phosphate dehydrogenase from Aspergillus niger. Arch. Biochem. Biophys. 1981, 211, 613-621. [CrossRef]

7. Niehaus, W.G.; Dilts, R.P. Purification and characterization of mannitol dehydrogenase from Aspergillus parasiticus. J. Bacteriol. 1982, 151, 243-250. [PubMed]

8. Jayashree, T.; Subramanyam, C. Oxidative stress as a prerequisite for aflatoxin production by Aspergillus parasiticus. Free Radic. Biol. Med. 2000, 29, 981-985. [CrossRef]

9. Reverberi, M.; Zjalic, S.; Ricelli, A.; Fabbri, A.A.; Fanelli, C. Oxidant/antioxidant balance in Aspergillus parasiticus affects aflatoxin biosynthesis. Mycotoxin Res. 2006, 22, 39-47. [CrossRef] [PubMed]

10. Narasaiah, K.V.; Sashidhar, R.B.; Subramanyam, C. Biochemical analysis of oxidative stress in the production of aflatoxin and its precursor intermediates. Mycopathologia 2006, 162, 179-189. [CrossRef] [PubMed]

11. Hong, S.Y.; Roze, L.V.; Wee, J.; Linz, J.E. Evidence that a transcription factor regulatory network coordinates oxidative stress response and secondary metabolism in aspergilli. Microbiologyopen 2013, 2, 144-160. [CrossRef] [PubMed]

12. Fanelli, C.; Fabbri, A.A.; Finotti, E.; Passi, S. Stimulation of aflatoxin biosynthesis by lipophilic epoxides. J. Gen. Microbiol. 1983, 129, 1721-1723. [CrossRef] [PubMed]

13. Huang, J.Q.; Jiang, H.F.; Zhou, Y.Q.; Lei, Y.; Wang, S.Y.; Liao, B.S. Ethylene inhibited aflatoxin biosynthesis is due to oxidative stress alleviation and related to glutathione redox state changes in Aspergillus flavus. Int. J. Food Microbiol. 2009, 130, 17-21. [CrossRef] [PubMed]

14. Reverberi, M.; Fabbri, A.A.; Zjalic, S.; Ricelli, A.; Punelli, F.; Fanelli, C. Antioxidant enzymes stimulation in Aspergillus parasiticus by Lentinula edodes inhibits aflatoxin production. Appl. Microbiol. Biotechnol. 2005, 69, 207-215. [CrossRef] [PubMed]

15. Caceres, I.; El Khoury, R.; Bailly, S.; Oswald, I.P.; Puel, O.; Bailly, J.D. Piperine inhibits aflatoxin B1 production in Aspergillus flavus by modulating fungal oxidative stress response. Fungal Genet. Biol. 2017, 107, 77-85. [CrossRef] [PubMed]

16. Mahoney, N.; Molyneux, R.J. Phytochemical inhibition of aflatoxigenicity in Aspergillus flavus by constituents of walnut (Juglans regia). J. Agric. Food Chem. 2004, 52, 1882-1889. [CrossRef] [PubMed]

17. Luo, X.; Affeldt, K.J.; Keller, N.P. Characterization of the far transcription factor family in Aspergillus flavus. G3 2016, 6, 3269-3281. [CrossRef] [PubMed]

18. Fasoyin, O.E.; Wang, B.; Qiu, M.; Han, X.; Chung, K.R.; Wang, S. Carbon catabolite repression gene creA regulates morphology, aflatoxin biosynthesis and virulence in Aspergillus flavus. Fungal Genet. Biol. 2018, 115, 41-51. [CrossRef] [PubMed]

19. Trapnell, C.; Williams, B.A.; Pertea, G.; Mortazavi, A.; Kwan, G.; van Baren, M.J.; Salzberg, S.L.; Wold, B.J.; Pachter, L. Transcript assembly and quantification by RNA-Seq reveals unannotated transcripts and isoform switching during cell differentiation. Nat. Biotechnol. 2010, 28, 511-515. [CrossRef] [PubMed]

20. Anders, S.; Huber, W. Differential expression analysis for sequence count data. Genome Biol. 2010, 11, R106. [CrossRef] [PubMed]

21. Amare, M.G.; Keller, N.P. Molecular mechanisms of Aspergillus flavus secondary metabolism and development. Fungal Genet. Biol. 2014, 66, 11-18. [CrossRef] [PubMed]

22. Georgianna, D.R.; Fedorova, N.D.; Burroughs, J.L.; Dolezal, A.L.; Bok, J.W.; Horowitz-Brown, S.; Woloshuk, C.P.; Yu, J.; Keller, N.P.; Payne, G.A. Beyond aflatoxin: Four distinct expression patterns and functional roles associated with Aspergillus flavus secondary metabolism gene clusters. Mol. Plant Pathol. 2010, 11, 213-226. [CrossRef] [PubMed]

23. Yu, J.; Chang, P.K.; Ehrlich, K.C.; Cary, J.W.; Bhatnagar, D.; Cleveland, T.E.; Payne, G.A.; Linz, J.E.; Woloshuk, C.P.; Bennett, J.W. Clustered pathway genes in aflatoxin biosynthesis. Appl. Environ. Microbiol. 2004, 70, 1253-1262. [CrossRef] [PubMed]

24. Bayram, O.; Krappmann, S.; Ni, M.; Bok, J.W.; Helmstaedt, K.; Valerius, O.; Braus-Stromeyer, S.; Kwon, N.J.; Keller, N.P.; Yu, J.H.; et al. VelB/VeA/LaeA complex coordinates light signal with fungal development and secondary metabolism. Science. 2008, 320, 1504-1506. [CrossRef] [PubMed]

25. Amaike, S.; Keller, N.P. Distinct roles for VeA and LaeA in development and pathogenesis of Aspergillus flavus. Eukaryot. Cell 2009, 8, 1051-1060. [CrossRef] [PubMed] 
26. Cary, J.W.; Harris-Coward, P.Y.; Ehrlich, K.C.; Mack, B.M.; Kale, S.P.; Larey, C.; Calvo, A.M. NsdC and NsdD affect Aspergillus flavus morphogenesis and aflatoxin production. Eukaryot. Cell 2012, 11, 1104-1111. [CrossRef] [PubMed]

27. Strijbis, K.; van den Burg, J.; Visser, W.F.; van den Berg, M.; Distel, B. Alternative splicing directs dual localization of Candida albicans 6-phosphogluconate dehydrogenase to cytosol and peroxisomes. FEMS Yeast Res. 2012, 12, 61-68. [CrossRef] [PubMed]

28. Abdollahi, A.; Buchanan, R.L. Regulation of aflatoxin biosynthesis: Induction of aflatoxin production by various carbohydrates. J. Food Sci. 1981, 46, 633-635. [CrossRef]

29. Maggio-Hall, L.A.; Keller, N.P. Mitochondrial $\beta$-oxidation in Aspergillus nidulans. Mol. Microbiol. 2004, 54, 1173-1185. [CrossRef] [PubMed]

30. Midgley, M. Carnitine acetyltransferase is absent from acuJ mutants of Aspergillus nidulans. FEMS Microbiol. Lett. 1993, 108, 7-10. [CrossRef] [PubMed]

31. Ruijter, G.J.; Visser, J. Carbon repression in Aspergilli. FEMS Microbiol. Lett. 1997, 151, 103-114. [CrossRef] [PubMed]

32. Cubero, B.; Scazzocchio, C. Two different, adjacent and divergent zinc finger binding sites are necessary for CREA-mediated carbon catabolite repression in the proline gene cluster of Aspergillus nidulans. EMBO J. 1994, 13, 407-415. [PubMed]

33. Balázs, A.; Pócsi, I.; Hamari, Z.; Leiter, É.; Emri, T.; Miskei, M.; Oláh, J.; Tóth, V.; Hegedûs, N.; Prade, R.A.; et al. AtfA bZIP-type transcription factor regulates oxidative and osmotic stress responses in Aspergillus nidulans. Mol. Genet. Genomics 2010, 283, 289-303. [CrossRef] [PubMed]

34. Sakamoto, K.; Arima, T.; Iwashita, K.; Yamada, O.; Gomi, K.; Akita, O. Aspergillus oryzae atfB encodes a transcription factor required for stress tolerance in conidia. Fungal Genet. Biol. 2008, 45, 922-932. [CrossRef] [PubMed]

35. Toone, W.M.; Morgan, B.A.; Jones, N. Redox control of AP-1-like factors in yeast and beyond. Oncogene 2001, 20, 2336-2346. [CrossRef] [PubMed]

36. Chang, P.K.; Scharfenstein, L.L.; Luo, M.; Mahoney, N.; Molyneux, R.J.; Yu, J.; Brown, R.L.; Campbell, B.C. Loss of $m s n A$, a putative stress regulatory gene, in Aspergillus parasiticus and Aspergillus flavus increased production of conidia, aflatoxins and kojic acid. Toxins 2011, 3, 82-104. [CrossRef] [PubMed]

37. Brown, S.H.; Scott, J.B.; Bhaheetharan, J.; Sharpee, W.C.; Milde, L.; Wilson, R.A.; Keller, N.P. Oxygenase coordination is required for morphological transition and the host-fungus interaction of Aspergillus flavus. Mol. Plant Microbe Interact. 2009, 22, 882-894. [CrossRef] [PubMed]

38. Affeldt, K.J.; Carrig, J.; Amare, M.; Keller, N.P. Global survey of canonical Aspergillus flavus G protein-coupled receptors. mBio 2014, 5, e01501-14. [CrossRef] [PubMed]

39. Badhani, B.; Sharma, N.; Kakkar, R. Gallic acid: A versatile antioxidant with promising therapeutic and industrial applications. RSC Adv. 2015, 5, 27540-27557. [CrossRef]

40. Yabe, K.; Nakajima, H. Enzyme reactions and genes in aflatoxin biosynthesis. Appl. Microbiol. Biotechnol. 2004, 64, 745-755. [CrossRef] [PubMed]

41. Buchanan, R.L.; Lewis, D.F. Regulation of aflatoxin biosynthesis: Effect of glucose on activities of various glycolytic enzymes. Appl. Environ. Microbiol. 1984, 48, 306-310. [PubMed]

42. Davis, N.D.; Diener, U.L. Growth and aflatoxin production by Aspergillus parasiticus from various carbon sources. Appl. Microbiol. 1968, 16, 158-159. [PubMed]

43. Ries, L.N.A.; Beattie, S.R.; Espeso, E.A.; Cramer, R.A.; Goldman, G.H. Diverse regulation of the CreA carbon catabolite repressor in Aspergillus nidulans. Genetics 2016, 203, 335-352. [CrossRef] [PubMed]

44. Payne, G.A.; Widstrom, N.W. Aflatoxin in maize. Crit. Rev. Plant Sci. 1992, 10, 423-440. [CrossRef]

45. Pfannenstiel, B.T.; Zhao, X.; Wortman, J.; Wiemann, P.; Throckmorton, K.; Spraker, J.E.; Soukup, A.A.; Luo, X.; Lindner, D.L.; Lim, F.Y.; et al. Revitalization of a forward genetic screen identifies three new regulators of fungal secondary metabolism in the genus Aspergillus. mBio 2017, 8, e01246-17. [CrossRef] [PubMed]

46. Lin, J.Q.; Zhao, X.X.; Wang, C.C.; Xie, Y.; Li, G.H.; He, Z.M. 5-Azacytidine inhibits aflatoxin biosynthesis in Aspergillus flavus. Ann. Microbiol. 2013, 63, 763-769. [CrossRef]

47. Trapnell, C.; Pachter, L.; Salzberg, S.L. TopHat: Discovering splice junctions with RNA-Seq. Bioinformatics 2009, 25, 1105-1111. [CrossRef] [PubMed]

48. Langmead, B.; Trapnell, C.; Pop, M.; Salzberg, S.L. Ultrafast and memory-efficient alignment of short DNA sequences to the human genome. Genome Biol. 2009, 10, R25. [CrossRef] [PubMed] 
49. Lim, F.Y.; Sanchez, J.F.; Wang, C.C.C.; Keller, N.P. Toward awakening cryptic secondary metabolite gene clusters in filamentous fungi. Methods Enzymol. 2012, 517, 303-324. [CrossRef] [PubMed]

50. Szewczyk, E.; Nayak, T.; Oakley, C.E.; Edgerton, H.; Xiong, Y.; Taheri-Talesh, N.; Osmani, S.A.; Oakley, B.R. Fusion PCR and gene targeting in Aspergillus nidulans. Nat. Protoc. 2007, 1, 3111-3120. [CrossRef] [PubMed]

51. Zhao, X.; Spraker, J.E.; Bok, J.W.; Velk, T.; He, Z.M.; Keller, N.P. A cellular fusion cascade regulated by LaeA is required for sclerotial development in Aspergillus flavus. Front. Microbiol. 2017, 8, 1925. [CrossRef] [PubMed]

(C) 2018 by the authors. Licensee MDPI, Basel, Switzerland. This article is an open access article distributed under the terms and conditions of the Creative Commons Attribution (CC BY) license (http:/ / creativecommons.org/licenses/by/4.0/). 